\title{
Characterization of the new dormitory towns visual environments and its perceptual influence on their residents
}

\author{
Nikita Luchinin ${ }^{1, *}$, Margarita Asylgaraeva ${ }^{1}$, and Sergey Startsev ${ }^{2}$, and Natal'ja Samosudova ${ }^{3}$ \\ ${ }^{1}$ Peter the Great St. Petersburg Polytechnic University, 195251, Polytechnicheskaya, 29, St. \\ Petersburg, Russia \\ ${ }^{2}$ LTD Biospeysstroy, CEO, 191023, Karavannaya 1, St. Petersburg, Russia \\ ${ }^{3}$ Moscow State University of Civil Engineering, Yaroslavskoye shosse, 26, Moscow, 129337, Russia
}

\begin{abstract}
The question of building a comfortable for living in it architectural space has gained a popularity because of the expansive growth of new dormitory towns in big Russian cities. Connection between the quality of surroundings and mental health of the residents, their ability to navigate in space and to react to the external stimuli is obvious. In this research the analysis of different typologies of urban architectural spaces was carried out in order to determine the quantitative parameters of these visual areas. According to the results of this research a strong tendency of the facades silhouettes simplification and a decrease of morphological informativeness of the visual environment were noticed. Comparing to other types of architectural environment, visual medium of new urban dormitory towns provides its observers with rather poor material to analyze and get important information from the surroundings. The whole spectrum of deviations from normal perceptive process can be influenced by this new environment, including difficulties with orientation in space, learning how to navigate (especially for kids who have lived in such conditions since being born), decrease concentration of attention and narrowing of the field of vision.
\end{abstract}

\section{Introduction}

New typology of urban residential areas has been developed over the past ten years in big Russian cities, which marks a new stage of evolution process since the introduction of mass development in the 50-s. New technologies brought to the construction site, development of the norms and building codes, use of new materials in construction - along with social changes in urban areas all these factors have helped to produce new dense clusters of residential high-rise buildings, as a rule in a considerable distance from the center. There is a necessity to monitor the interaction of this new type of surroundings with residents as a need to make a comfortable environment to live and to spend time in is still actual: this

\footnotetext{
*Corresponding author: luchinin1nikita@gmail.com
} 
problem is not a new one, but since urban areas get new features and new characteristics, it becomes important to determine them.

Development of such interdisciplinary scientific studies as Architectural Psychology and Environmental Psychology in the 60-s from one point of view corresponds to the trend of mass architecture humanization. But the humanization should not be considered as an intentional aim for new researches - in fact it was a need to cover the shortcomings in the mass production practices in different spheres. Critical evaluation of the used building methods, results of this process and the need for changes - all that have become widely discussed after decades of first experiments. Using new researches in the scientific studies such as Neurology, Psychology, Behavioral Psychology we can analyze how being in urban architectural environment can affect different parts of nervous system, health and behavior. There is a need to determine the cause-and-effect relationship between characteristics of an architectural look of the area and deviations in behavior, health conditions and psychological state of an observer in order to know how to regulate the negative effects of this interaction.

The aim of this research is to identify features of the new dormitory town architectural environment in a big Russian city and to analyze them in relation to the impact they can bring on health conditions, behavior and mental state of the observer.

\section{Literature analysis}

Last century introduction of a new way to describe and think of a human brain and psychological activity affected architecture as well as other fields of knowledge. In cooperation with another idea of thinking about organization of human life as a system - socalled ecological approach these influences gave new information to be mentioned in the context of architecture and urbanism.

Process of human perception were described long ago, but since new discoveries have been made in the last century, and one of the most recent descriptions of the process has been made by James J. Gibson in his book "The ecological approach to visual perception" [1]. According to Gibson and other authors, the process of perception has four main stages: perception, attributive stage, expectation stage, and affective stage. During the first stage a pattern of light from the outside is perceived by an eye retina, which is covered with nerve cells. After that raw sensory data goes to the brain of an observer in a form of electrical charges of different strength. During the attributive stage the image received by the observer is compared with all data of the past experiences contained in the part of unconscious memory. In a situation when there is no such information in the memory of the observer, which can be associated with a new visual data, it becomes necessary to study the new information, to look closer and check if it is dangerous for the human health. During the expectation stage the observer using imagination, associations, and experience establishes the conceived image with sequences of events and creates extensions of the visible world in his mind. Finally, during affective stage the brain indicates the importance of what the eyes have perceived and chooses the model of behaviour to use in such conditions. The emotional response is the main part of the affective stage of perception.

The object of this research, architectural environment, becomes the factor which directly impacts the process of human perception on all these stages.

With help of an eye-tracking method developed initially by professor A. L. Jarbus and nowadays technologically advanced by Ann Sussman [2] it has become possible to understand the mechanism of unconscious eye movements during the visual perception these movements are usually called saccades. Saccades are not coordinated by the head brain but occur simultaneously - this phenomenon was studied and described by V.A. Filin $[3,4]$. Different researches show that during the observation of an architectural environment the large areas contours (fields such as houses facades, large areas of glazing, roads, etc.) as well 
as the peak points and the crosses of such contours lines, small accents, and outstanding from the background details become the main fixation points for the eyes of an observer $[5,6,7]$. In his book called "Videoecology" V.A. Filin goes further and gives the description of two types of uncomfortable for visual perception fields - aggressive and homogenic [3]. An aggressive visual field represents an apparent field with a huge number of visually similar details which configurations are simple and monotonously repetitive, while a homogenic field represents an apparent field where it is difficult to find even one element in it and visually recognizable contours of large areas are partly or totally absent. These two types of apparent fields are considered as uncomfortable for eyes to look at because they affect the saccades automaticity, the phenomenon standing behind the process of searching for a next eye fixation point.

\section{Methods of research}

In order to determine the qualities of an architectural environment, according to a series of assumptions the methodology was developed, and it is based mainly on the existing ways to describe the visual field of the environment. Parameters of a visual field used in this research were studied separately by different authors: the theory of the buildings contour morphological informativeness was developed by O. A. Fomenko [5], the idea to categorize the visual fields by the quantity of details and their type of alternation was proposed by $\mathrm{V}$. A. Filin [3], the theory of visual complexity and composition of the architectural details goes back a long way, however in the book "The Dynamics of Architectural Form" by R. Arnheim [8] it is given some new meanings in the context of human perception of architectural space. Moreover, there were noticed the visual properties of space responsible for the observer's navigation in it studied by Ann Sussman, Jan Gehl and others [2, 9, 10]. Overall analyses of the set of chosen parameters became the main principle of the new methodology.

As an object of the research a conditional model of an urban architectural environment was taken - a photographical street view, eye-level shot. Classification of the urban types of environment has been made during the selection of the materials stage. Ten photos per each of 6 types of environment were analysed: a dormitory town formed during the $60-80 \mathrm{~s}$, a dormitory town formed after the 2010s, a historical centre, a business quarter, a low-rise quarter, and an industrial area. Descriptions of all types are shown in Table 1.

Table 1. Typologies of the researched urban architectural environments.

\begin{tabular}{|c|l|l|l|l|}
\hline Type & \multicolumn{1}{|c|}{ Description } & \multicolumn{1}{|c|}{ Type of buildings } & \multicolumn{1}{c|}{ Type of flows } & Photo example \\
\hline A & $\begin{array}{l}\text { Dormitory town, } \\
\text { formed during the } \\
60-80 \text { s }\end{array}$ & $\begin{array}{l}\begin{array}{l}\text { Prefabricated panel } \\
\text { houses, masonry walls, } \\
\text { plastering and ceramic } \\
\text { tiles lining, 5-15 floors. }\end{array} \\
\text { B }\end{array}$ & $\begin{array}{l}\text { Traffic flow by the quarters } \\
\text { periphery, inside the } \\
\text { quarter the flows are } \\
\text { combined - cars and } \\
\text { pedestrians. }\end{array}$ \\
\hline \multirow{3}{*}{$\begin{array}{l}\text { Dormitory town, } \\
\text { formed after the } \\
2010 \mathrm{~s}\end{array}$} & $\begin{array}{l}\text { Frame houses with } \\
\text { masonry walls or walls } \\
\text { made concrete blocks or } \\
\text { panels. Usually the } \\
\text { ventilated façade } \\
\text { technology is } \\
\text { implemented with metal } \\
\text { tiles or panels with } \\
\text { plastering used as the } \\
\text { coating; 12-28 floors. }\end{array}$ & $\begin{array}{l}\text { Traffic is only in the } \\
\text { periphery, inside the } \\
\text { quarter the flows are } \\
\text { combined. }\end{array}$ & \\
\hline
\end{tabular}




\begin{tabular}{|c|l|l|l|l|}
\hline C & Historical centre & $\begin{array}{l}\text { Diversity in building } \\
\text { typologies and types of } \\
\text { exterior finishing, 2-10 } \\
\text { floors. }\end{array}$ & $\begin{array}{l}\text { Combined, but the priority } \\
\text { is mainly given to the } \\
\text { pedestrians. }\end{array}$ \\
\hline $\mathrm{D}$ & Business quartal & $\begin{array}{l}\text { Frame buildings with } \\
\text { great areas of walls } \\
\text { made of glazing, 5-60 } \\
\text { floors. }\end{array}$ & $\begin{array}{l}\text { Vehicle traffic connection } \\
\text { with other city parts, inside } \\
\text { the quarter mainly a } \\
\text { pedestrian traffic. }\end{array}$ \\
\hline $\mathrm{E}$ & Low-rise quartal & $\begin{array}{l}\text { Apartment houses either } \\
\text { made of timber or stone } \\
\text { and brick with } \\
\text { plastering, siding and } \\
\text { tiles as finishing; 1-5 } \\
\text { floors. }\end{array}$ & $\begin{array}{l}\text { Vehicle traffic connection } \\
\text { with other city parts, } \\
\text { practically no connection } \\
\text { between the houses inside } \\
\text { the quarter. }\end{array}$ \\
\hline F & Industrial area & $\begin{array}{l}\text { Frame buildings with } \\
\text { ribbon glazing and big } \\
\text { tiles or siding, or brick } \\
\text { masonry; 1-5 floors. }\end{array}$ & $\begin{array}{l}\text { Priority is given to the } \\
\text { vehicle traffic. }\end{array}$ \\
\hline
\end{tabular}

The parameters chosen to characterize the visual fields of the architectural environment types are as follows: a quantity of assumed fixation points, a quantity of visually distinguishable systems to organize a façade space, relational area of the aggressive and homogenic fields and relational area, occupied by the facades, façade contour complexity.

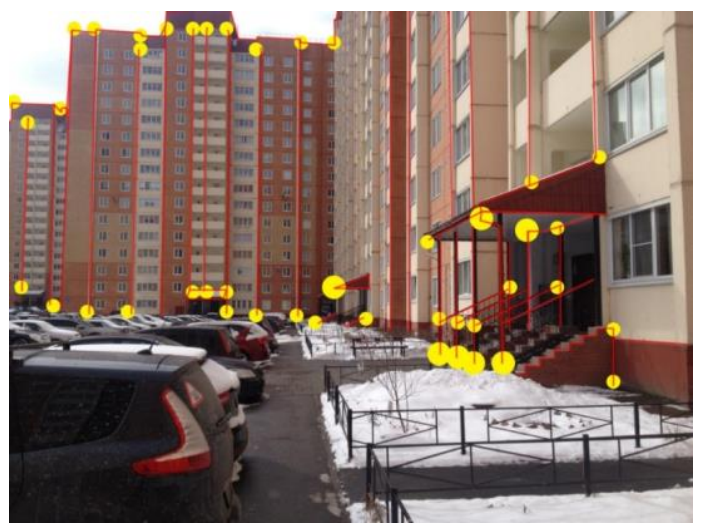

Fig. 1 Example of a photo analysis showing the fixation points (environment type - B).

The quantity of the assumed fixation points was determined as the quantity of façade contours peak points along with points of contours line intersection, counted during the period of 3 seconds by one observer. As contours lines the contours of clearly visible elements and details of the facades were counted. Example of such an analysis with fixation points highlighted is shown on Figure 1.

In terms of visually distinguishable system to organize façade space, the composition of elements arrangement on the façade space with distinguishable rules of organisation was considered. The interval for recognition of such systems was chosen also as 3 seconds. 
Relational area of the aggressive and homogenic fields and relational area occupied by the facades were determined as the ratio between the specified areas and the total area of the photo. There were several conditions imposed to consider the area to be homogenic: the quantity of visible elements in the area should be no more than 2, the ratio between the area occupied by elements and the homogenic area should be no more than 0.1 , and one or several lines of the areas contour should be absent or blurry. Also, the conditions for consideration the area as aggressive are as follows: the quantity of similar elements of the same typology should be more than 8 , the distances between these elements should be equal and visually smaller than the length of the elements, and the difficulties arising to determine the exact number of such elements without calculations.

Complexity of the contours was calculated as the ratio between the length of the line comprising the edge of a plain shape by which the façades can be replaced and the area limited by the façade contour and such line (Figure 2).

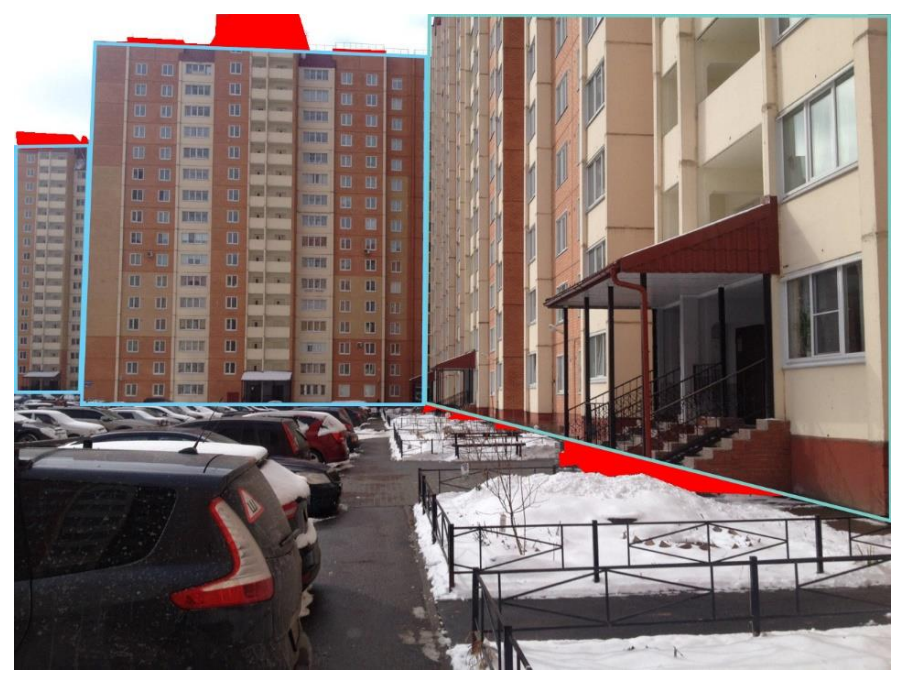

Fig. 2 Example of a contour complexity determination (environment type - B).

\section{Results and discussion}

Results of this research are presented in the Graphs 1-4.

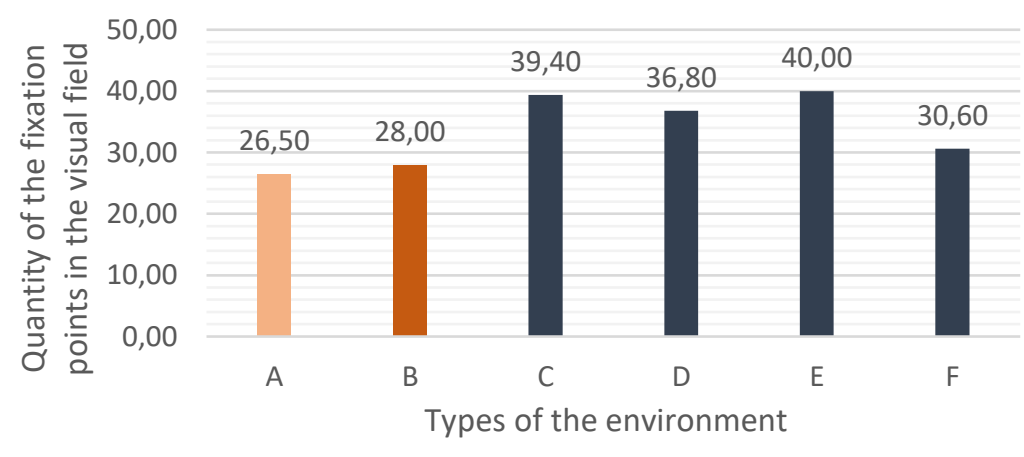

Graph 1. Average quantity of fixation points in the visual fields according to the environment typologies. 


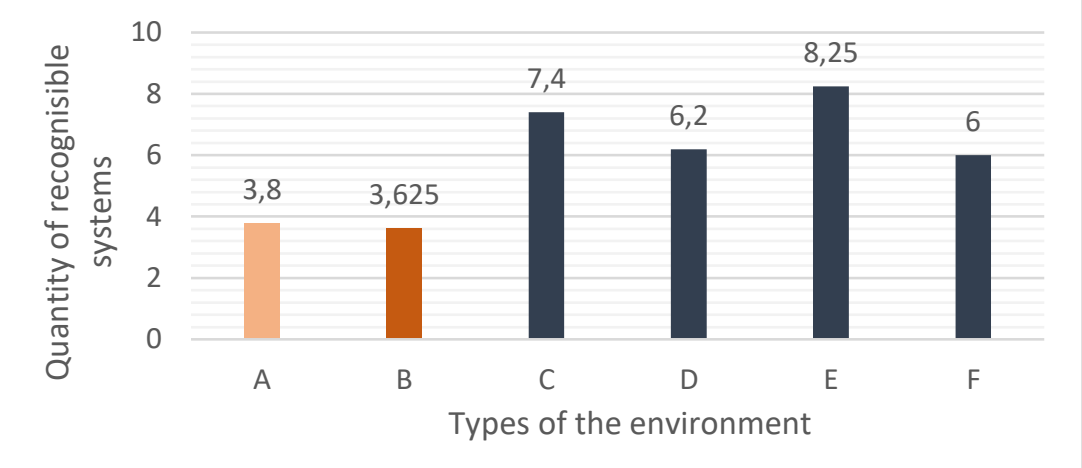

Graph 2. Average quantity of the recognisable facades system organizations in the visual fields according to the environment typologies.

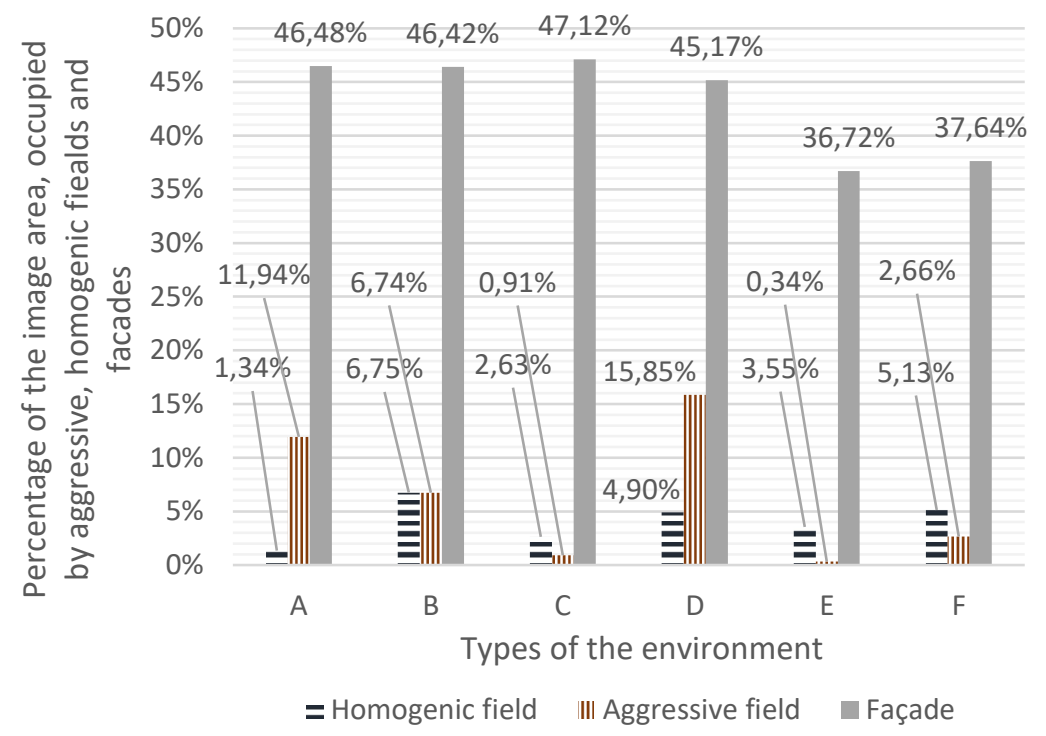

Graph 3. Percentage of the visual fields area occupied by aggressive, homogenic fields and by buildings facades, according to the environment typologies.

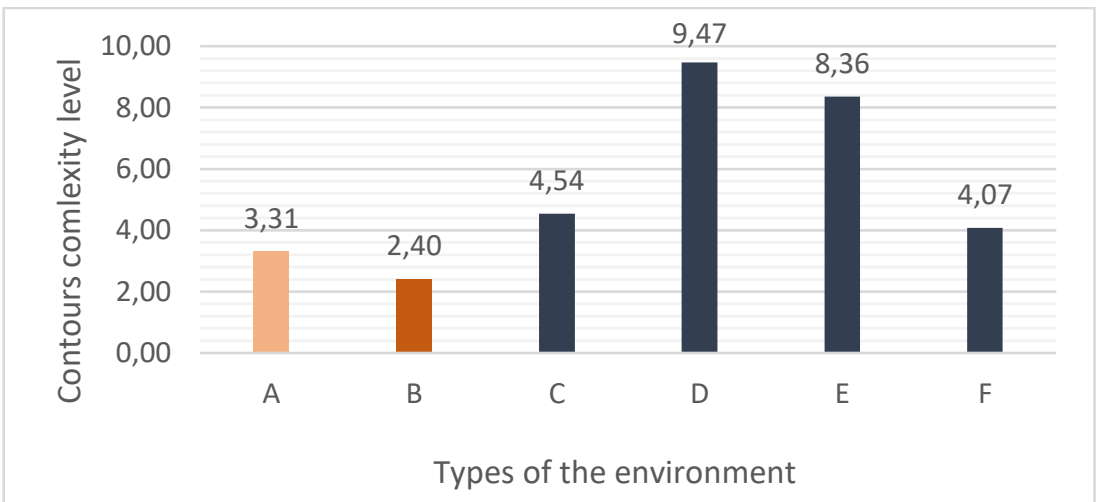

Graph 4. Average level of facades contour complexity in the visual fields according to the environment typologies. 
One of the main observation from the graphs is that characteristics of the type A and type $\mathrm{B}$ visual fields have certain resemblance in contrast to the values of other types of fields parameters. Especially this trend is noticeable in the Graph 4 representing the level of contours complexity between all types of the environment. Taking into account the fact that facades contours are the formgivers to the environment informativeness for the observer and affect its conditions and perception of space [5,11], the environments A and B provide less information for the observer to percept. In this occasion the observer has difficulties with remembering and identifying the new and familiar silhouettes of architectural objects buildings outlines and their silhouettes against the sky. During the stage of perception when an observer explores the environment he involuntarily compares the new visual information he gets with the existing memory of the experienced appearance. With a poor information from the environment types A and B this natural process becomes complicated and confusing. Especially these characteristics of environment can affect the developing mechanism of child's perception.

In addiction to the decrease in a level of contours complexity in the environments of types $\mathrm{A}$ and $\mathrm{B}$ there is a minimum number of the fixation points in these visual fields among all the types. Taking into account that aggressive and homogenic fields are usually ignored by the eyes saccades (average percentage of area occupied by an aggressive visual field in the environment type $\mathrm{A}$ is $12 \%$ and type $\mathrm{B}-6.75 \%$; percentage of area occupied by a homogenic visual field in the environment type $\mathrm{A}$ is $1.34 \%$ and type $\mathrm{B}-6.75 \%$ ), the actual potential of the visual field to produce fixation points for the observer is even less. Unit value of the fixation point quantity (not considering the blind zones - aggressive and homogenic fields) for the environment type A is 0.008 points/pixel, for type B is 0.0085 points/pixel, and for the types $\mathrm{C}, \mathrm{D}, \mathrm{E}, \mathrm{F}$ is $0.009,0.0151 .0 .0122$ and 0.0103 points/pixel respectively.

Another tendency is visible in the Graph 2 - a relatively small number of visually recognizable systems for the façade space organization in the environments of type A and B. This observation represents the fact, that it takes less time to study the façade of a building and also it takes less time to track the contours. It can be stated that the visual field becomes banal and non-interesting, the new information and new stimulus are minor and weak. Moreover, these stimuli do not suggest the observer the desire to look closer at details and do not encourage to pay attention to something, which can be both dangerous and helpful.

What is significant is that the actual visual field can be overcrowded with elements, details and stimuli, for example, advertisements on the shops or a panorama of different buildings, but still the parameters of such field are similar to the parameters of the banal field lacking information. Here the reason can be in the difficulties to the observer to find the hierarchy of the stimuli and to find out which object in the field is more important than the others.

According to the results of this research it can be said that dormitory towns built massively from the 60 -s until the end of the last century and the dormitory towns formed no longer than ten years ago and still growing now have the same difference from the rest of the city - they provide rather simple, banal and lacking to give new information environment which is not easy to observe, use, and perceive. Talking about an ecological approach to analyze the impact of the environment and its visual compound on the residents and potential observers the changes of scene, described previously, are definitely entail the changes in perception habits, models of reaction, and interaction with new spaces. The most striking effect of the environmental changes is seen when talking about children and teenagers living constantly in new conditions. Described in the research quantitative changes of the visual field observed by the residents of dormitory towns can be compared with the new researches in the field of neuroscience and psychology, made in the last years by the authors such as Lisa Feldman Barrett, Robert Gifford, Harry Frances Mallgrave, and others [12,13,14]. The cumulative use of the researches in these scientific fields and analyses of urban environment 
changes can become the basis for the further determination of sustainable urban environment organization conditions.

\section{References}

1. J. Gibson, The perception of the visual world (Boston : Houghton Mifflin The Riverside Press, 1950)

2. A. Sussman, J. Hollander, Cognitive Architecture : Designing for How We Respond to the Built Environnent (New York : Routledge, 2015)

3. V.A. Filin, Videoecology (Moscow : TASS-Reklama, 1997)

4. V.A. Filin, Vestnik Mezhdunarodnoj akademii nauk. Russkaya sekciya, 2, 43-50 (2006)

5. S. Chechelnytskiy, O. Fomenko, Visual ecology of the architectural environment (Kharkov : Torsing, 2012)

6. O. Fomenko, Morphologicheskaya informativnost architekturnogo obraza (Kharkov : Torsing, 2002)

7. A. Moles, Théorie de l'information et perception esthétique (Paris, Denoël, 1973)

8. R. Arnheim, The Dynamics of Architectural Form Based on the 1975 Mary Duke Biddle Lectures at the Cooper Union (Berkeley : University of California, 1977)

9. J. Gehl J, L. Johansen L, S. Reigstad, Urban design, 11, 29-47 (2006)

10. M. Bhatt, J. Suchan, C. Schultz, V. Kondyli, S. Goyal, AAAI, 4349-4350 (2016)

11. S. Chechelnytskiy, Metody informazionnogo analiza morfologii gorodskoj sredy (Kharkov, 2006)

12. L.F. Barrett, Annual Review of Psychology, 58, 373-403 (2008)

13. R. Gifford, Environmental Psychology: Principles and Practice (5th ed.) (Colville, WA : Optimal Books, 2014)

14. H.F. Mallgrave, Architecture and Neuroscience, A Tapio Wirkkala - Rut Foundation, 22-42 (2015) 